\title{
A 3-year dataset of sensible and latent heat fluxes from the Tibetan Plateau, derived using eddy covariance measurements
}

\author{
Maoshan Li • Wolfgang Babel • Xuelong Chen • \\ Lang Zhang • Fanglin Sun • Binbin Wang • \\ Yaoming Ma • Zeyong Hu • Thomas Foken
}

Received: 29 June 2014 / Accepted: 8 October 2014 / Published online: 28 October 2014

(C) The Author(s) 2014. This article is published with open access at Springerlink.com

\begin{abstract}
The Tibetan Plateau (TP) has become a focus of strong scientific interest due to its role in the global water cycle and its reaction to climate change. Regional flux estimates of sensible and latent heat are important variables for linking the energy and hydrological cycles at the TP's surface. Within this framework, a 3-year dataset (2008-2010) of eddy covariance measured turbulent fluxes was compiled from four stations on the TP into a standardised workflow: corrections and quality tests were applied using an internationally comparable software package. Second, the energy balance closure $\left(C_{\mathrm{EB}}\right)$ was determined and two different closure corrections applied. The four stations (Qomolangma, Linzhi, NamCo and Nagqu) represent different locations and typical land surface types on the TP (high altitude alpine steppe with sparse vegetation, a densely vegetated alpine meadow, and bare soil/gravel, respectively). We show that the $C_{\mathrm{EB}}$ differs
\end{abstract}

M. Li $(\bowtie) \cdot$ F. Sun $\cdot$ Z. Hu

Key Laboratory of Land Surface Process and Climate Change in Cold and Arid Regions, Cold and Arid Regions Environmental and Engineering Research Institute, Chinese Academy of Sciences, Lanzhou, China

e-mail:mshli@lzb.ac.cn

M. Li $\cdot$ X. Chen

Faculty of Geo-Information Science and Earth Observation,

University of Twente, Enschede, The Netherlands

W. Babel · T. Foken

Department of Micrometeorology, University of Bayreuth, Bayreuth, Germany

L. Zhang $\cdot$ B. Wang $\cdot$ Y. Ma

Institute of Tibetan Plateau Research, Chinese Academy of Sciences, Beijing, China

T. Foken

Member of Bayreuth Centre of Ecology and Environmental Research (BayCEER) of the University of Bayreuth, Bayreuth, Germany between each surface and undergoes seasonal changes. Typical differences in the turbulent energy fluxes occur between the stations at Qomolangma, Linzhi and NamCo, while Nagqu is quite similar to NamCo. Specific investigation of the pre-monsoon, the Tibetan Plateau summer monsoon, postmonsoon and winter periods within the annual cycle reinforces these findings. The energy flux of the four sites is clearly influenced by the Tibetan Plateau monsoon. In the pre-monsoon period, sensible heat flux is the major energy source delivering heat to the atmosphere, whereas latent heat flux is greater than sensible heat flux during the monsoon season. Other factors affecting surface energy flux are topography and location. Land cover type also affects surface energy flux. The energy balance residuum indicates a typically observed overall non-closure in winter, while closure (or 'turbulent over-closure') is achieved during the Tibetan Plateau summer monsoon at the Nagqu site. The latter seems to depend on ground heat flux, which is higher in the wet season, related not only to a larger radiation input but also to a thermal decoupling of dry soils. Heterogeneous landscape modelling using a MODIS product is introduced to explain energy non-closure.

\section{Introduction}

Exchanges in heat energy, momentum and mass are key variables for land surface processes affected by atmospheric circulation and climate, and provide feedback for atmospheric dynamics and climate change. The TP is the world's largest alpine ecosystem, with an average altitude of $>4,000 \mathrm{~m}$ a.s.l. across $25^{\circ}$ of longitude. Because of its effect on the regional, and global, energy and water cycles, the TP has been the subject of climate study since the mid-twentieth century (Yeh et al. 1957; Flohn 1957). A series of atmospheric science 
expeditions have been carried out on the TP (e.g. the 'First Tibetan Plateau Meteorological Science Experiment, 1979', 'Tibetan Plateau Surface Heat Resource Observations' (Ji et al. 1986), the 'Second Tibetan Plateau Meteorological Science Experiment (TIPEX)' (Xu et al. 2002) and the 'Coordinated and Enhanced Observation Period (CEOP) of the Asian-Australian Monsoon Project in Tibet (CAMPTibet)' (Wang et al. 1999; Koike et al. 1999; Ma et al. 2005, 2006)). Recently, the Chinese National Key Programme for Developing Basic Sciences and the Third Pole Environment (TPE) reported on its work on the TP and its environs. The dynamic and thermodynamic effects of the TP have been explored using these observational datasets. They show that sensible heat flux transfer dominates the pre-Asian monsoon period, while a latent heat flux prevails during the summer monsoon period, except for the western TP (Chen et al. 1985). Energy imbalance is obvious in the monsoon season (Bian et al. 2002; Yang et al. 2004). Previous studies show that before the onset of the monsoon, the TP is the major energy source providing sensible heat flux to the atmosphere ( $\mathrm{Li}$ and Yanai 1996). During the rainy season, the latent heat released to the atmosphere is the dominant heat source over the eastern $\mathrm{TP}$, whereas sensible heat flux is comparable to latent heat flux over the western TP (Chen et al. 1985). Over the past 50 years, scientists have paid much attention to this kind of research over the TP. The first Qinghai-Xizang Plateau Meteorological Experiment in 1979 obtained some important results: during the dry period, sensible heat flux is the major energy source delivering heat to the atmosphere, whereas latent heat flux is greater than sensible heat flux during the wet period (Zhang et al. 1988). In summer, the plateau surface is a heat source, and in the dry period, sensible heat flux is the major heat source; during the rainy season, the latent heat flux becomes as important as the sensible heat flux (Qian and Jiao 1997). Several studies of turbulent energy flux have been conducted on the TP. For instance, Yeh and Gao (1979) obtained a vertically integrated mean heat source of $138 \mathrm{~W} / \mathrm{m}^{-2}$ over the western TP in June, whereas Chen et al. (1985) estimated it as $37 \mathrm{~W} / \mathrm{m}^{-2}$. This large discrepancy was caused by the different drag coefficients used in the bulk method, resulting in the sensible heat fluxes differing by a factor of 2-3. Li et al. (2001) reported a wide range of drag coefficients (i.e. $2.5 \times$ $10^{-3}$ to $12 \times 10^{-3}$ ) over the TP despite using the same data. Latent heat flux vis-à-vis residual surface energy can be estimated as a budget. However, this approach is prone to error because of the significant imbalance in the energy budget on the TP (10-40\%) which has been reported (Kim et a1. 2001; Bian et al. 2002). A network of atmospheric boundary layer and turbulence flux measurement stations was set up in 1998 at the beginning of the GEWEX Asia Monsoon Experiment in Tibet (GAME-Tibet, 1996-2000) and the CEOP of CAMP-Tibet to make long-term, and continually improved, observations. Although many studies have explored the characteristics of turbulent fluxes over the TP using these observational data (Ma et al. 2003; Tanaka et al. 2003; Gu et al. 2005; Liu et al. 2009; Yao et al. 2011; Bian et al. 2012; Zhang et al. 2013), uncertainties within these approaches remain substantive. The eddy covariance (EC) method can be applied to reduce these uncertainties. Shi and Liang suggest that land-biosphere-atmosphere interactions may regulate the temporal variation of the surface-sensible and latent heat fluxes, although the magnitude of such couplings has seasonal dependence (Shi and Liang 2014). However, they do not provide a detailed analysis.

This study will focus on establishing a consistent framework for turbulent flux analysis, quality assessment, $C_{\mathrm{EB}}$ and landscape heterogeneity, and analyse differences/ characteristics in the observations at different places on the TP. Section 3 introduces the turbulence data and quality assessment, while Section 4 focuses on $C_{\mathrm{EB}}$, prior to our conclusion.

\section{Measurement set-up}

Heterogeneity in the TP region exists due to both orography and a patchy land use structure. Measuring sites therefore included locations in the Qomolangma valleys (Qomo) in the southern TP and in the Linzhi valleys (Linz) close to the forested southeastern TP, as well as sites on the banks of NamCo Lake (Namc) and on the Nagqu grasslands (BJ) in the central TP (Table 1 and Fig. 1). Mainly grassland sites (three stations) and gravel fields (one station) were probed. The four stations represent different locations and typical land surface types on the TP (high altitude alpine steppe with sparse vegetation, densely vegetated alpine meadow and bare soil/gravel) (Table 1 and Fig. 1). The EC measuring technique was applied in order to provide high-quality and continuous surface turbulent flux data for momentum and sensible and latent heat. The typical EC measuring set-up consisted of a sonic anemometer (CSAT3, Campbell Scientific, Inc.) and a fast-response hygrometer (LI-7500 open-path gas analyser, Li-COR Biosciences) (Table 1). The EC system at all stations was installed before May $2010 \mathrm{ca} .3 \mathrm{~m}$ above ground level, except at the BJ site, where EC equipment was set up $20 \mathrm{~m}$ above ground level. The sampling frequency of the EC raw data was $10 \mathrm{~Hz}$. The time zone used was Beijing Standard Time (UTC $+8 \mathrm{~h}$ ). Additionally, soil and radiation measurements as well as standard surface meteorological data were recorded at all of the sites for 2008-2010. The four radiation components were measured at a height of $1.20 \mathrm{~m}$ with CNR1 equipment (Kipp \& Zonen, Delft, Netherlands) for all sites except the BJ site, where shortwave net radiation components were measured using a CM21 machine (Kipp \& Zonen, Delft, Netherlands), and longwave components with an Eppley PIR device (Eppley Laboratory, Inc.) at a height of $1.40 \mathrm{~m}$ above 
Table 1 Turbulence measurement sites on the TP. Given are the coordinates (latitude, longitude), the altitude (m a.s.l.) and the EC set-up (sonic anemometer, hygrometer-CSAT3, sonic anemometer by Campbell Scientific Inc., USA; LI-7500, open-path $\mathrm{CO}_{2} / \mathrm{H}_{2} \mathrm{O}$ gas analyser by LI-COR Biosciences, USA). The 'land use' column indicates the land cover type

\begin{tabular}{|c|c|c|c|c|c|}
\hline Site & $\begin{array}{l}\text { Coordinates } \\
\text { (lat., long.) }\end{array}$ & $\begin{array}{l}\text { Alt. } \\
\text { (m a.s.1.) }\end{array}$ & Land use & $\begin{array}{l}\text { Sonic } \\
\text { anemometer }\end{array}$ & Hygrometer \\
\hline Qomolangma & $28^{\circ} 21^{\prime} 29^{\prime \prime} \mathrm{N}, 86^{\circ} 56^{\prime} 47^{\prime \prime} \mathrm{E}$ & 4,293 & Bare soil/gravel & CSAT3 & LI-7500 \\
\hline Linzhi & $\begin{array}{l}29^{\circ} 45^{\prime} 56.3^{\prime \prime} \mathrm{N} \\
94^{\circ} 44^{\prime} 18.0^{\prime \prime} \mathrm{E}\end{array}$ & 3,327 & Alpine grassland & CSAT3 & LI-7500 \\
\hline NamCo & $\begin{array}{l}30^{\circ} 46^{\prime} 22.21^{\prime \prime} \mathrm{N} \\
90^{\circ} 57^{\prime} 46.87^{\prime \prime} \mathrm{E}\end{array}$ & 4,730 & Alpine steppe & CSAT3 & LI-7500 \\
\hline Nagqu & $\begin{array}{l}31^{\circ} 22^{\prime} 7.18^{\prime \prime} \mathrm{N} \\
91^{\circ} 53^{\prime} 55.36^{\prime \prime} \mathrm{E}\end{array}$ & 4,502 & Alpine steppe & $\begin{array}{l}\text { Kaijo Denki, type DA- } 600 \\
\quad \text { (before May 2010), and CSAT3 }\end{array}$ & LI-7500 \\
\hline
\end{tabular}

ground level. Subsurface soil heat flux values at 0.05 and $0.10 \mathrm{~m}$ depths were measured with a HFP01 heat flux plate (Hukseflux Thermal Sensors) at all sites. Soil temperatures at $0.05,0.10,0.20,0.40,0.80$ and $1.60 \mathrm{~m}$ depths were measured using a TR219-L sensor at the BJ site and a PT100 device (Vaisala) at the Qomo, Linz and Namc sites. Soil moisture at $0.05,0.10,0.20,0.40,0.80$ and $1.60 \mathrm{~m}$ depths was measured using a CS616-L water content reflectometer (Campbell Scientific, Inc.) at the BJ site and a Theta Probe Soil Moisture Sensor ML2x (Delta-T Devices, Ltd.) at the Qomo, Linz and Namc sites. Precipitation was measured using a Geonor (model T-200B) precipitation weighing gauge (Geonor, Inc.), which allows the measurement of both liquid and solid precipitation.

\section{Turbulence data processing}

\subsection{TK3 processing}

The EC flux dataset of all the turbulence data was processed and quality-controlled using the TK3 software package developed by the Department of Micrometeorology, University of Bayreuth (Mauder and Foken 2011). Following Mauder et al. (2006), the processing steps and flux corrections listed below were applied to the EC raw data.

- Calculation of averages, variances and covariances for using averaged 30-min intervals and taking into consideration the time delays between different sensors, and

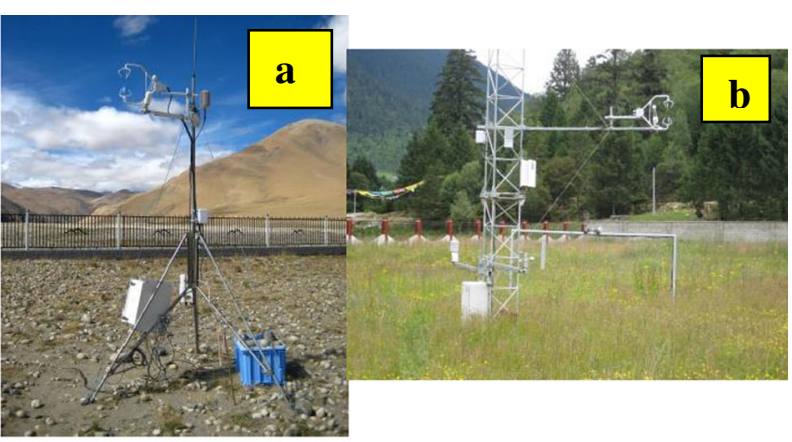

$30^{\circ} \mathrm{N}$
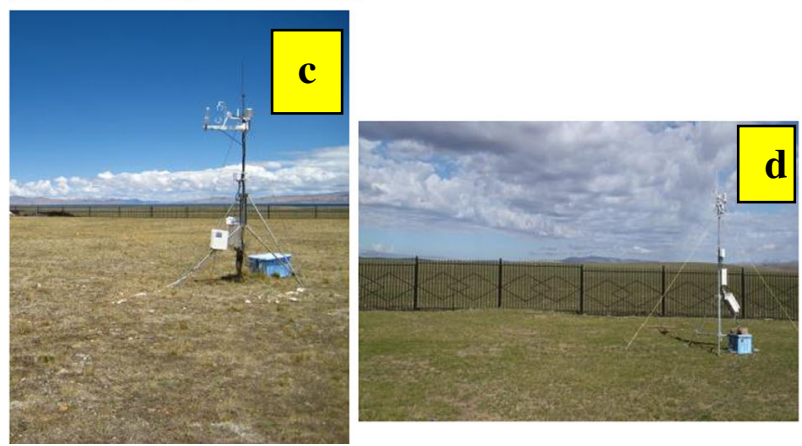

Fig. 1 Topographic map (left) and underlying surface conditions (right) of the turbulence measuring sites on the TP. Filled circles show the locations of the four stations: a Qomolangma (Qomo), b Linzhi (Linz), c NamCo (Namc) and d Nagqu (BJ) 
excluding physically invalid values and spikes (Vickers and Mahrt 1997);

- Cross-wind correction of the sonic temperature if necessary (depending on sonic anemometer type).

- Planar fit coordinate rotation (Wilczak et al. 2001);

- Correction of spectral loss due to path-length averaging, spatial separation of the sensors and the dynamic frequency effect of signals (Moore 1986);

- Conversion of buoyancy into sensible heat flux (Schotanus et al. 1983; Liu et al. 2001);

- Correction of density fluctuations (WPL correction) to determine fluxes in the scalar quantities of $\mathrm{H}_{2} \mathrm{O}$ and $\mathrm{CO}_{2}$ (Webb et al. 1980; Fuehrer and Friehe 2002; Liebethal and Foken 2003, 2004).

The impact of these processing and flux-correction steps on flux estimates and $C_{\mathrm{EB}}$ has been discussed in Mauder et al. (2006). Quality tests implemented using TK3 consist of a stationarity test and a test of the fulfilment of integral turbulence characteristics (ITC) for each turbulent flux (Foken and Wichura 1996; Foken et al. 2004). According to Rebmann et al. (2005), the final quality flag (1-5) is assigned to a specific half-hourly turbulent flux value by combining the quality flags for stationarity and ITC. Classes $1-2$ can be used for fundamental research and classes 3-4 for general use such as continuously running systems. Turbulent flux values marked with a class 5 quality flag should be rejected.

\subsection{Energy balance closure}

A possible residuum of the surface energy balance, $Q_{\text {res }}$, was evaluated at all the measuring sites in the turbulence network where additional radiation and soil measurements were carried out and turbulent fluxes of sensible heat, $Q_{\mathrm{H}}$, and latent heat, $Q_{\mathrm{E}}$, were measured. At the surface, the net radiation, $Q_{\mathrm{S}}$, is transformed into $Q_{\mathrm{H}}$ and $Q_{\mathrm{E}}$ and into the ground heat flux, $Q_{\mathrm{G}}$, thus:

$-Q_{\mathrm{S}}=Q_{\mathrm{H}}+Q_{\mathrm{E}}+Q_{\mathrm{G}}+Q_{\mathrm{res}}$.

The heat storage in the upper soil layer is included in the value of $Q_{\mathrm{G}}$ and was calculated according to the method of Yang and Wang (2008). Other storage terms (plants, air, etc.) and photosynthesis can be neglected as they are usually very small for low-level vegetation (Foken 2008). Two methods have been applied to correct an unclosed energy balance. One method is to preserve the Bowen ratio (EBC-Bo), as in Twine et al. (2000). This means the residuum is divided up according to the Bowen ratio $\left(\mathrm{Bo}=Q_{\mathrm{H}} / Q_{\mathrm{E}} ; Q_{\mathrm{H}}\right.$, sensible heat; $Q_{\mathrm{E}}$, latent heat) and distributed to sensible and latent heat accordingly. The Bowen ratio after correction is the same as before. The correction is only applied when both sensible and latent heat flux exceed $10 \mathrm{~W} / \mathrm{m}^{2}$ (and Bo $>0$ ).

The second method corrects the turbulent fluxes according to their contribution to the buoyancy flux $Q_{\mathrm{HB}}$ (EBC-HB). The background is based on the theoretical influence of secondary circulations, which are mainly driven by buoyancy (e.g. Foken et al. 2011). According to the secondly circulation theory, the buoyancy flux, $Q_{\mathrm{B}}$, is defined as:

$$
Q_{\mathrm{B}}=\rho c_{p} w^{\prime} T_{v}^{\prime}=\rho c_{p}\left(w^{\prime} T^{\prime}+0.61 T w^{\prime} q^{\prime}\right)=Q_{\mathrm{H}}\left(1+0.61 T \frac{c_{p}}{\lambda B_{o}}\right)
$$

Details can be found in Charuchittipan et al. (2014).

The sensible and latent heat flux are calculated as follows, after correction with EBC-HB:

$Q_{\mathrm{H}}^{\mathrm{EBC}-\mathrm{HB}}=Q_{\mathrm{H}}+f_{\mathrm{HB}} Q_{\mathrm{res}}$

$Q_{\mathrm{E}}^{\mathrm{EBC}-\mathrm{HB}}=Q_{\mathrm{E}}+\left(1-f_{\mathrm{HB}}\right) Q_{\mathrm{res}}$ with $f_{\mathrm{HB}}=\frac{Q_{\mathrm{H}}}{Q_{\mathrm{B}}}=\left(1+0.61 T \frac{c_{p}}{\lambda \cdot B_{o}}\right)^{-1}$

where with the residual $Q_{\text {res }}, c_{p}$ is the air heat capacity and $\lambda$ is the heat of evaporation.

There is a weak dependency of EBC-HB on air temperature $T$. For $f_{\mathrm{HB}}=1,>90 \%$ of the residual $Q_{\text {res }}$ is added to the sensible heat flux, whereas for $f_{\mathrm{HB}}=0.1$, it is ca. $60 \%$. As the method does not preserve the Bowen ratio, EBC-HB is calculated iteratively until $f_{\mathrm{HB}}$ converges. Similar to EBC-Bo, the correction is only applied when both sensible and latent heat flux exceed $10 \mathrm{~W} / \mathrm{m}^{2}$.

The principal exceptions vis-à-vis the selected data for calculating surface energy fluxes were as follows:

(a) Deleted EBC values vis-à-vis contributions by targeted land use to turbulent fluxes were $<50 \%$ (Linzhi only); and

(b) Ground heat flux measurements were shifted forward 30 min due to soil measurement delays (NamCo only).

Exception (a) arose because the land surface features of the Linzhi site are very complex, with river, road, forest, hill, etc. The surface heterogeneity within the footprint area can be seen in Fig. 2. It shows the cumulative flux contributions (isopleths) for 2008 for the Linzhi site's different land uses. Flux contribution clearly varies with differing land use. The $50 \%$ flux contribution area reached the road in the east and the river in the north and was limited to $100 \times 100 \mathrm{~m}^{2}$. This is why we selected the $<50 \%$ flux contribution data. 


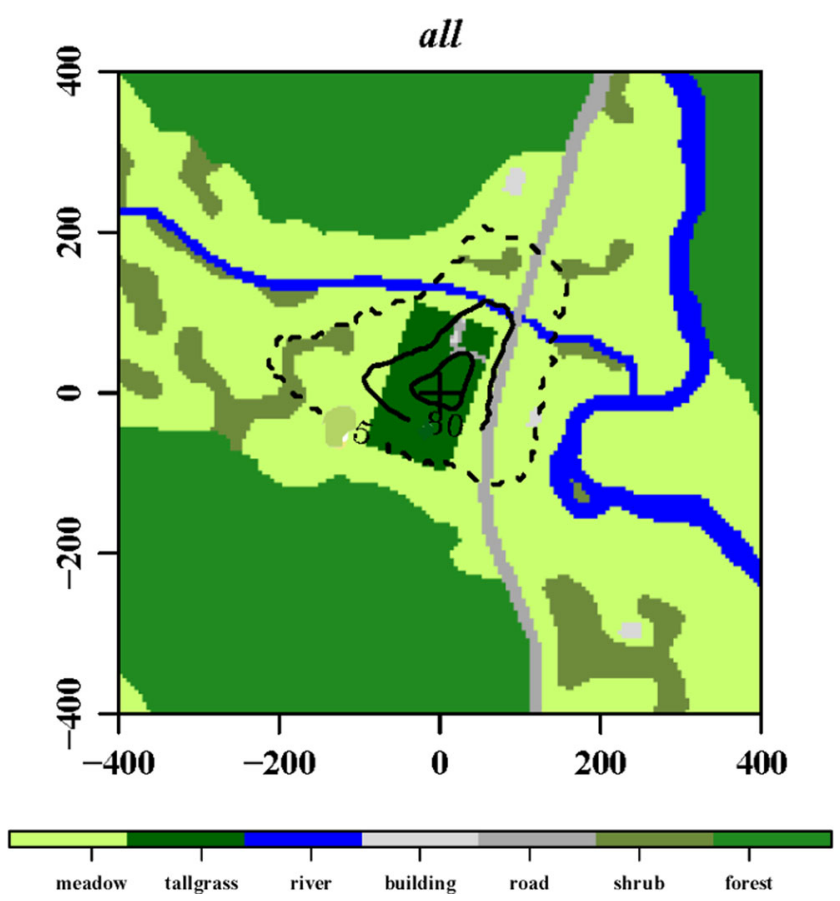

Fig. 2 Spatial distribution of land use combined with the relative flux contributions in the Linzhi area under all conditions (including unstable, neutral and stable). The black isolines indicate the rate of flux contribution as 80,50 and $5 \%$ from inner to outer isoline, respectively. Plus sign is the location of the Linzhi station

\section{Results and discussion}

\subsection{Impact of the monsoon on surface fluxes}

Variations in energy fluxes vis-à-vis monsoon exchange were calculated for the Qomolangma, Linzhi, NamCo and Nagqu sites (Fig. 2). Past literature shows that the onset of the summer monsoon on the TP occurs in June, continues through July and August, begins to retreat in September and disappears by mid-October (Xu and Gao 1962). We therefore defined March, April and May (MAM) as pre-monsoon; June, July, August and September (JJAS) as monsoon; October and November (ON) as post-monsoon; and December, January and February (DJF) as winter. Surface energy fluxes in winter are lower than those of other seasons for the four sites, indicating weak heat exchange. In the premonsoon period, $Q_{\mathrm{H}}$ increases with rising net radiation values, while $Q_{\mathrm{E}}$ and $Q_{\mathrm{G}}$ remain low. At the Linzhi site, $Q_{\mathrm{H}}$ increases slowly in the morning in winter and spring due to the extensive grassland coverage, and $Q_{\mathrm{G}}$ registers higher values than other fluxes. As the monsoon approaches, $Q_{\mathrm{E}}$ increases and becomes greater than $Q_{\mathrm{H}}$ at all sites except Qomolangma. In the winter and pre-monsoon periods, a bell-shaped Rnet curve is visible at all sites, indicating mostly clear and sunny days, with no disturbance from cloud shadow. During the monsoon and post-monsoon periods, the Qomolangma, Linzhi and
NamCo sites show decreases in Rnet between 1400 and 1600 hours, and between 1200 and 1400 hours for the Nagqu site; these falls are related to convective clouds. Rnet is higher in the monsoon period than in others due to low albedo at all sites (Table 2 and Fig. 3).

As described above, $Q_{\mathrm{E}}$ is higher than $Q_{\mathrm{H}}$ during the monsoon season, except at the Qomolangma site. The impact of the monsoon on the surface energy flux component at all four sites differs depending on their location. Figure 2 shows daily energy flux curves from 2008 to 2010 averaged according to different seasons and locations. In the winter and premonsoon periods, $Q_{\mathrm{H}}$ is higher than $Q_{\mathrm{E}}$. The seasonal averaged $Q_{\mathrm{H}}$ maximum is between 180 and $200 \mathrm{~W} / \mathrm{m}^{2}$ at 1400 hours at the Qomolangma site. As the surface is dry and there is low evaporation, $Q_{\mathrm{E}}$ is low at ca. $10 \mathrm{~W} / \mathrm{m}^{2} ; Q_{\mathrm{G}}$ is also low, though higher than $Q_{\mathrm{E}}$. A possible reason is the pre-monsoon period's thermal decoupling of dry soils in response to the dry surface and partial net radiation $\left(Q_{\mathrm{S}}\right)$. In the monsoon season, $Q_{\mathrm{E}}$ and $Q_{\mathrm{G}}$ increase to a maximum of $100 \mathrm{~W} / \mathrm{m}^{2}$ at midday. The energy flux residuum is nearly $200 \mathrm{~W} / \mathrm{m}^{2}$ and higher than that in the pre-monsoon season. The high $Q_{\mathrm{E}}$ and $Q_{\mathrm{G}}$ values at the Linzhi site are due to the extensive grass cover. $Q_{\mathrm{G}}$ values are negative after midday, resulting from the snow or ice cover. During the monsoon season, vapour water and evaporation rates increase. $Q_{\mathrm{E}}$ is clearly dominant (above $200 \mathrm{~W} /$ $\mathrm{m}^{2}$ ) and is higher than $Q_{\mathrm{H}}$. At the NamCo site, temporal variations in $Q_{\mathrm{H}}$ are the same as at the Qomolangma and Linzhi sites in the pre-monsoon period. However, $Q_{\mathrm{E}}$ is higher than $Q_{\mathrm{H}}$ during the monsoon season, while $Q_{\mathrm{G}}$ increases and reaches $200 \mathrm{~W} / \mathrm{m}^{2}$ at noon. The residuum is high in the premonsoon period, but low during the monsoon season.

Another difference is that net radiation is higher in the monsoon period than in the pre-monsoon period at these sites, resulting from greater albedo in the latter period (Table 2 and Fig. 3). Downwelling shortwave radiation is greater in the pre-monsoon period than other periods due to clear skies and low humidity values, except for the Linzhi site. Albedo values are smaller during the monsoon season than other periods, except at Linzhi, with an almost constant value of 0.18 for every period but winter. Albedo values are higher at Qomolangma than at the other sites, except during the post-monsoon period.

The Bowen ratio for the Linzhi site is the smallest of all four sites, with a value of 0.63 . This shows that latent heat flux is higher than sensible heat flux due to increase in evaporation in the southeastern TP during the pre-monsoon period. The Bowen ratio is $>1$ at Qomolangma throughout the year, demonstrating that $Q_{\mathrm{H}}$ is always higher than $Q_{\mathrm{E}}$.

The energy flux of the four sites is clearly influenced by the monsoon. In the pre-monsoon period, $Q_{\mathrm{H}}$ is higher than the other parameters, with a maximum value 
Table 2 Albedo and Bowen ratio (Bo) from 2008 to 2010, averaged for the different seasons (pre-monsoon, monsoon, post-monsoon and winter) and locations: Qomolangma (Qomo), Linzhi (Linz), NamCo (Namc) and Nagqu (BJ)

\begin{tabular}{|c|c|c|c|c|c|c|c|c|}
\hline \multirow[t]{2}{*}{ Sites } & \multicolumn{2}{|c|}{ Pre-monsoon } & \multicolumn{2}{|c|}{ Monsoon } & \multicolumn{2}{|c|}{ Post-monsoon } & \multicolumn{2}{|l|}{ Winter } \\
\hline & Albedo & Bo & Albedo & Bo & Albedo & Bo & Albedo & Bo \\
\hline Qomo & 0.28 & 4.48 & 0.23 & 1.20 & 0.27 & 3.43 & 0.33 & 8.04 \\
\hline Linz & 0.19 & 0.63 & 0.18 & 0.27 & 0.17 & 0.63 & 0.20 & 2.37 \\
\hline Namc & 0.24 & 1.55 & 0.18 & 0.50 & 0.29 & 0.82 & 0.28 & 1.68 \\
\hline BJ & 0.26 & 1.22 & 0.19 & 0.41 & 0.30 & 1.32 & 0.30 & 7.53 \\
\hline
\end{tabular}

of $200 \mathrm{~W} / \mathrm{m}^{2}$. Other factors affecting surface energy flux are topography and location. At the Linzhi site in
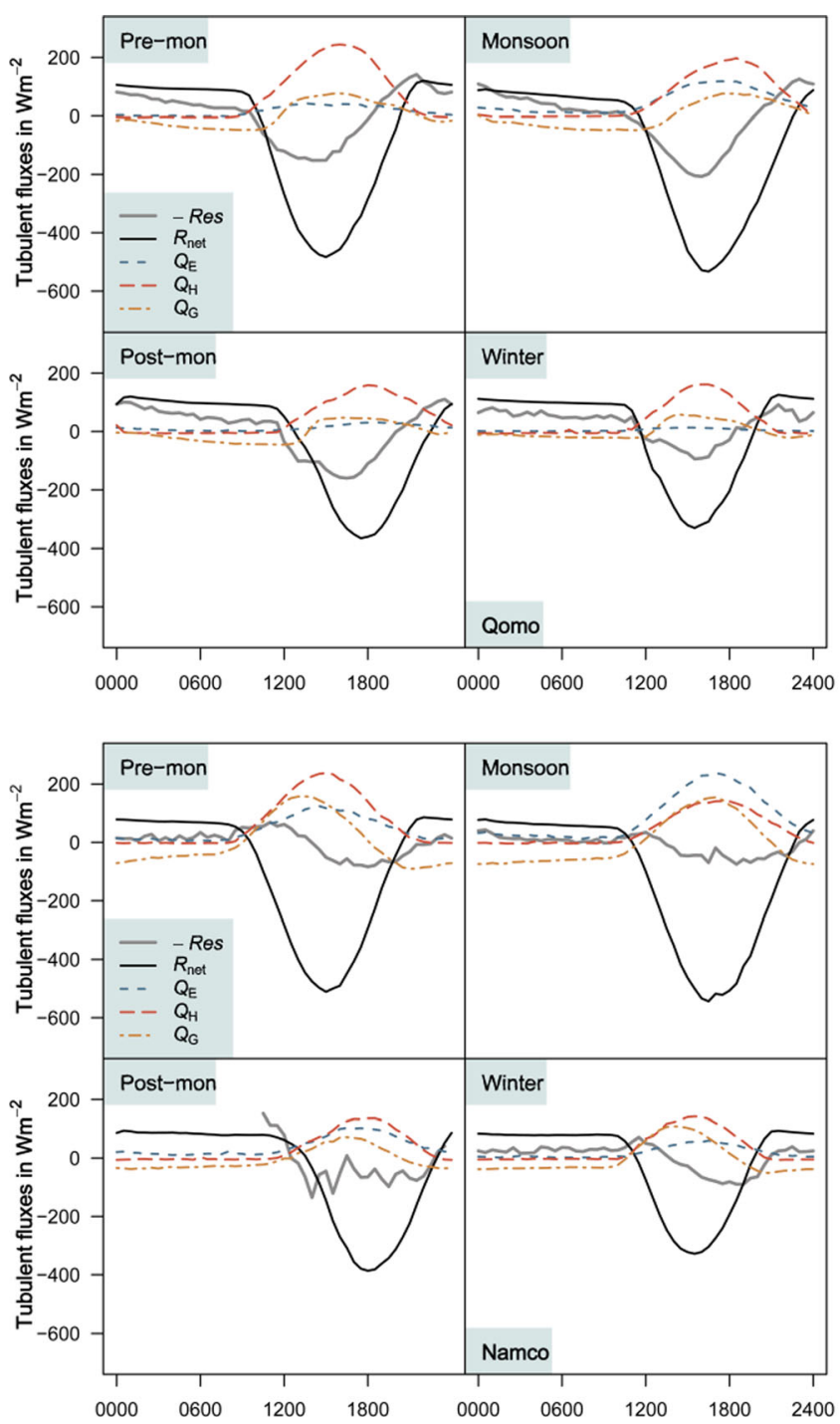

Fig. 3 Surface net radiation $\left(R_{\text {net }}\right)$ and turbulent heat fluxes (sensible heat flux $\left(Q_{\mathrm{H}}\right)$, latent heat flux $\left(Q_{\mathrm{E}}\right)$ and ground heat flux $\left(Q_{\mathrm{G}}\right)$ ) from 2008 to 2010 , averaged for the different seasons (pre- the southeastern TP, $Q_{\mathrm{H}}$ is $<200 \mathrm{~W} / \mathrm{m}^{2}$ in the premonsoon period, though $Q_{\mathrm{E}}$ increases and exceeds
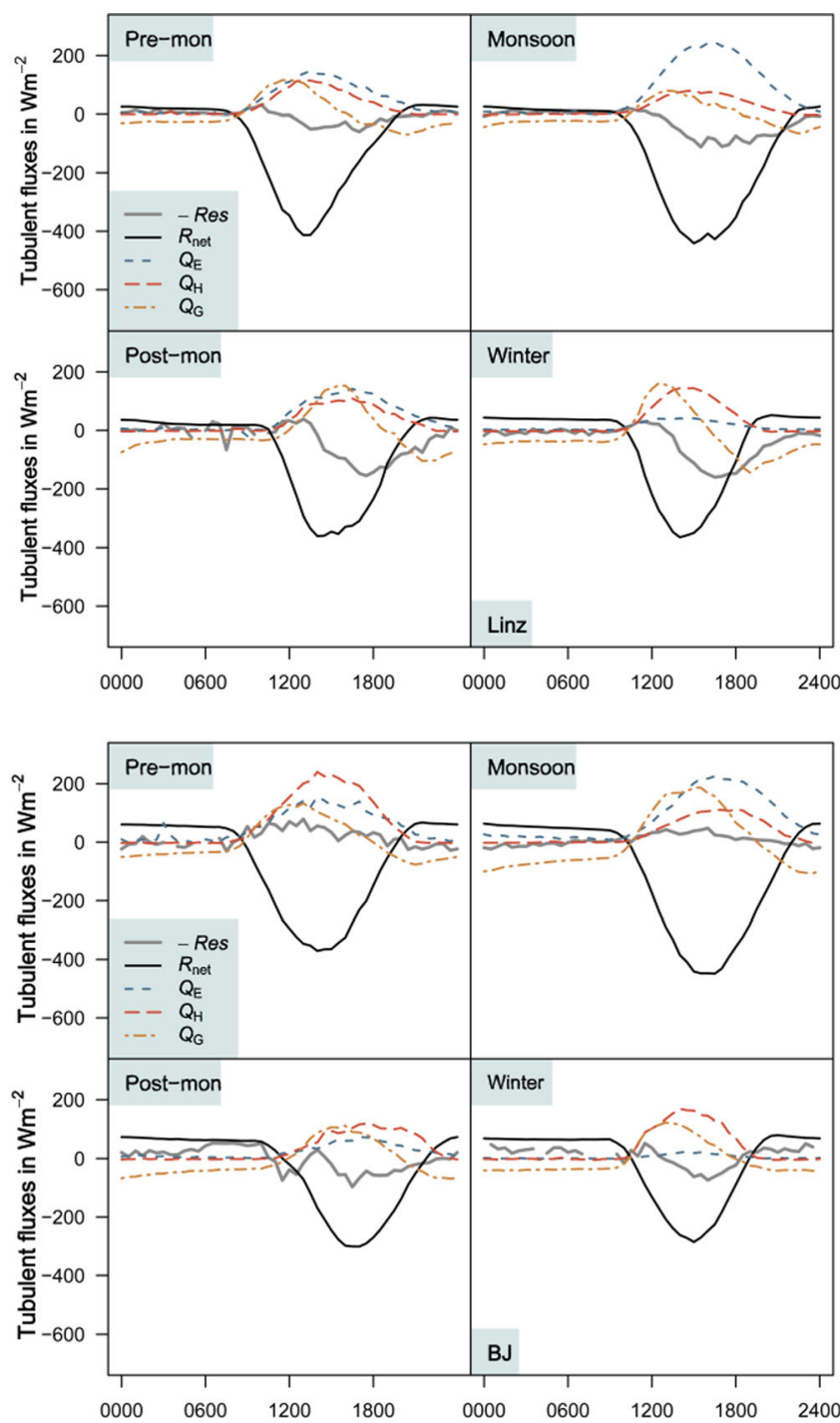

monsoon, monsoon, post-monsoon and winter) and locations: Qomolangma (Qomo), Linzhi (Linz), NamCo (Namc) and Nagqu (BJ). $-Q_{\text {res }}$ is the energy flux residuum 
$200 \mathrm{~W} / \mathrm{m}^{-2}$ during the monsoon season. The type of land cover also affects surface energy flux. For example, $Q_{\mathrm{E}}$ is low at the Qomolangma site even during the monsoon as it is covered by bare soil and gravel; the heat from radiation heats the surface and thus increases surface temperatures, which are converted to $Q_{\mathrm{H}}$, meaning $Q_{\mathrm{H}}$ remains high during the monsoon season and exceeds $Q_{\mathrm{E}}$. Conversely, $Q_{\mathrm{G}}$ is low in the pre-monsoon period, except at Linzhi, while it increases during the monsoon season. At the Linzhi site, $Q_{\mathrm{G}}$ remains low during the monsoon season due to the dense vegetative cover. Some of the $Q_{\mathrm{S}}$ is stored in the vegetation and cannot be transferred into the soil. Consideration of the energy balance should therefore include its interception by vegetation. Here, we can typically see that the residuum indicates overall non-closure in the winter (DJF), while closure (or 'turbulent over-closure') is achieved in the summer at the Nagqu site, for example. Such a circumstance seems to depend on ground heat flux, which is higher in the wet season, as related to a higher radiation input on the one hand, and a thermal decoupling of dry soils on the other. If the Nagqu case is typical, then the scale mismatch (turbulence measurements over the dryer upwind region (Van der Velde et al. 2012) and soil measurements in the wetter regions) is the main reason for the different closure values for different periods.

\subsection{Energy balance closure and landscape heterogeneity}

\subsubsection{Energy balance closure}

In this study, the Bowen ratio closure can be used to correct the energy balance of EC measurements at the four sites. This computation assumes that $f_{\mathrm{HB}}$ has been correctly measured by the EC system, so that individual values of $Q_{\mathrm{H}}$ and $Q_{\mathrm{E}}$ can be adjusted to balance Eq. 1 . The principle for selecting data for calculating $C_{\mathrm{EB}}$ is the same as that for calculating surface energy fluxes. Averaged $C_{\mathrm{EB}}$ is $61,76,78$ and $107 \%$ at Qomolangma,
Linzhi, NamCo and Nagqu, respectively. The correlation coefficient is $0.7,0.73,0.68$ and 0.69 for the four sites, respectively.

Regarding the 3-year database, the surface energy balance residuum is 39,24 and $22 \%$ at Qomolangma, Linzhi and NamCo, respectively. This is comparable with the ranges reported on the TP by Kim et a1. (2001) and Bian et al. (2002) (10-40\% residuum). However, there is a negative residuum of $-7 \%$ at the Nagqu station. This finding supports the hypothesis that homogeneous areas such as deserts (homogeneous on larger scales than the footprint scale) close the energy balance better than heterogeneous sites (Heusinkveld et al. 2004; Mauder et al. 2007; Foken et al. 2011). Indeed, Nagqu is the most homogeneous site compared to Qomolangma, NamCo and Linzhi. There are different $C_{\mathrm{EB}}$ values for different periods. The surface energy balance residuum during the pre-monsoon and monsoon periods is lower than during the post-monsoon and winter periods at all the sites.

$C_{\mathrm{EB}}$ values differ with the approach of the season. Higher $C_{\mathrm{EB}}$ values occur during the pre-monsoon and monsoon seasons at the four sites (Table 3 and Fig. 4). Qomolangma's $C_{\mathrm{EB}}$ value of $65 \%$ in the pre-monsoon period is the lowest; this was $81 \%$ at Linzhi and NamCo, and $>121 \%$ at Nagqu. During the monsoon season, $C_{\mathrm{EB}}$ values were $60,76,76$ and $1.11 \%$ at Qomolangma, Linzhi, NamCo and Nagqu, respectively. During the winter, $C_{\mathrm{EB}}$ is the lowest for all sites, at $<70 \%$ (energy residuum was $>30 \%$ ). The lowest $C_{\mathrm{EB}}$ value was $45 \%$ at Qomolangma. $C_{\mathrm{EB}}$ values are overbalanced at the Nagqu site during the pre-monsoon and monsoon periods.

The apparently disparate scatterplot might be related to differences in ground heat flux calculations. The $C_{\mathrm{EB}}$ values might therefore be biased by the scale mismatch between EC measurements, soil measurements and radiation measurements, especially at the Nagqu site, where the $20 \mathrm{~m}$ height footprint is very large, and the westerly upwind region is dryer (Van der Velde et al. 2012). Soil

Table $3 C_{\mathrm{EB}}$, mean value $(\mu)$ and variance $\left(\sigma^{2}\right)$ of the EVI in the different seasons (pre-monsoon, monsoon, post-monsoon and winter) and locations: Qomolangma (Qomo), Linzhi (Linz), NamCo (Namc) and Nagqu (BJ)

\begin{tabular}{|c|c|c|c|c|c|c|c|c|c|c|c|c|}
\hline \multirow[t]{2}{*}{ Sites } & \multicolumn{3}{|c|}{ Pre-monsoon } & \multicolumn{3}{|c|}{ Monsoon } & \multicolumn{3}{|c|}{ Post-monsoon } & \multicolumn{3}{|c|}{ Winter } \\
\hline & $C_{\mathrm{EB}}$ & $\mu$ & $\sigma^{2}\left(\times 10^{-3}\right)$ & $C_{\mathrm{EB}}$ & $\mu$ & $\sigma^{2}\left(\times 10^{-3}\right)$ & $C_{\mathrm{EB}}$ & $\mu$ & $\sigma^{2}\left(\times 10^{-3}\right)$ & $C_{\mathrm{EB}}$ & $\mu$ & $\sigma^{2}\left(\times 10^{-3}\right)$ \\
\hline Qomo & 0.65 & 0.08 & 0.31 & 0.60 & 0.08 & 0.36 & 0.54 & 0.08 & 0.43 & 0.55 & 0.07 & 0.35 \\
\hline $\operatorname{Linz}$ & 0.81 & 0.02 & 1.38 & 0.76 & 0.24 & 3.45 & 0.72 & 0.24 & 3.44 & 0.61 & 0.02 & 3.26 \\
\hline Namc & 0.81 & 0.09 & 0.39 & 0.76 & 0.15 & 1.20 & 0.66 & 0.11 & 0.32 & 0.68 & 0.07 & 0.40 \\
\hline BJ & 1.21 & 0.10 & 0.57 & 1.11 & 0.15 & 1.20 & 0.80 & 0.12 & 0.62 & 0.65 & 0.10 & 0.88 \\
\hline
\end{tabular}



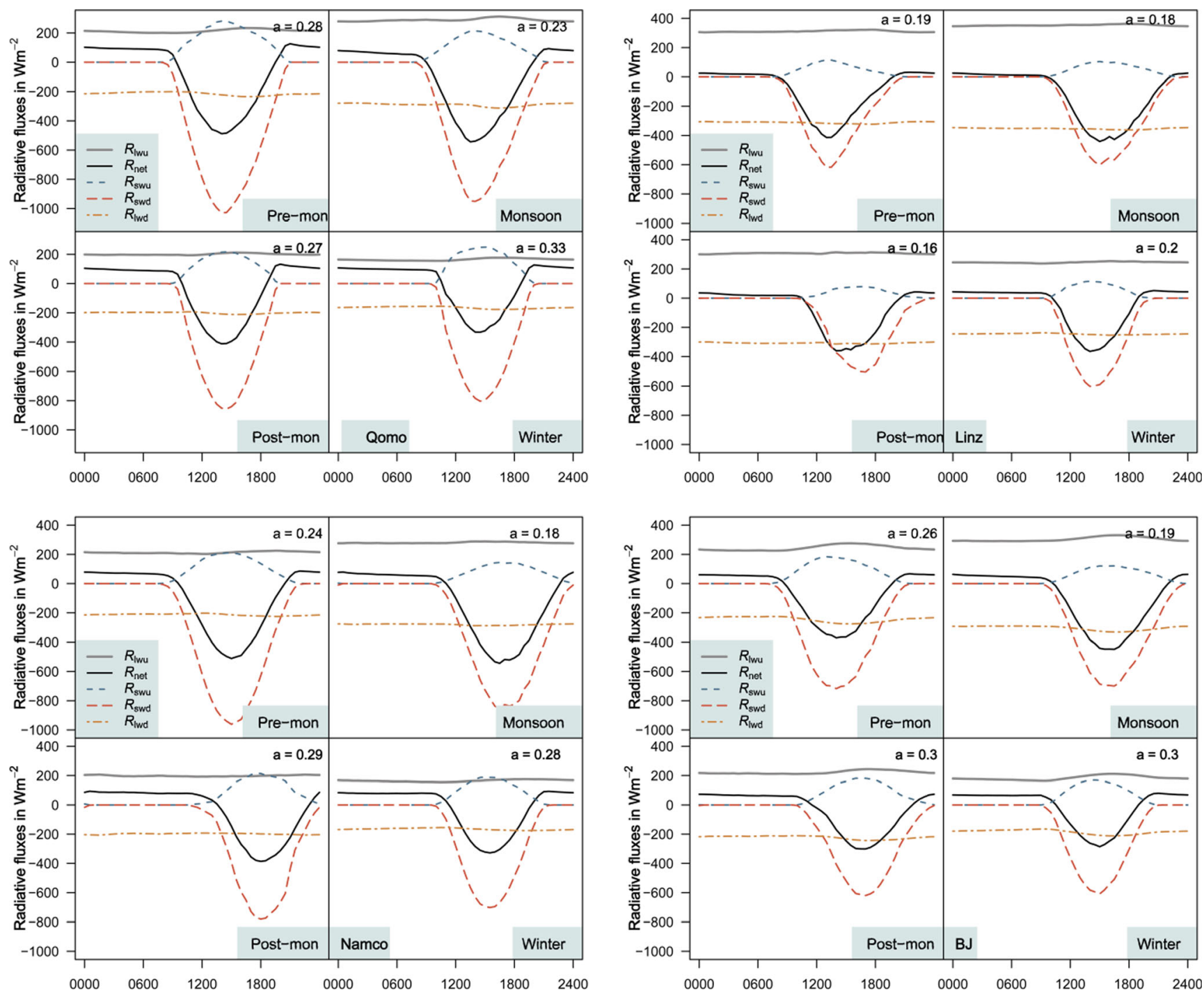

Fig. 4 Surface radiation fluxes: downward shortwave radiation $\left(R_{\mathrm{swd}}\right)$; upward shortwave radiation $\left(R_{\mathrm{swu}}\right)$; downward longwave radiation $\left(R_{\mathrm{lwd}}\right)$; and upward longwave radiation $\left(R_{\text {lwu }}\right)$ from 2008 to 2010, averaged for

the different seasons (pre-monsoon, monsoon, post-monsoon and winter) and locations: Qomolangma (Qomo), Linzhi (Linz), NamCo (Namc) and Nagqu (BJ). $R_{\text {net }}$ is surface net radiation. $\alpha$ is albedo

and radiation properties might therefore be different from the ones measured at the station.

Table 3 shows that the $C_{\mathrm{EB}}$ is higher during the premonsoon and monsoon periods, with a lower mean value $(\mu)$ for the enhanced vegetable index (EVI), except at the Qomolangma site. This could explain the high $C_{\mathrm{EB}}$ during the pre-monsoon and monsoon periods. It is complicated and problematic using variance $\left(\sigma^{2}\right)$ to explain $C_{\mathrm{EB}}$. Furthermore, the glacial wind and mountain-valley wind effect (Sun et al. 2007; Li et al. 2012) at Qomolangma have important consequences for the non-closure of the surface energy balance during the daytime. The advection produced by glacial and mountain-valley winds leads to a large residuum at the Qomolangma site. To verify this, diurnal variations in wind direction in 2010 were investigated. Figure 5 shows that glacial winds (northeasterly and southerly wind) prevailed from morning to afternoon during the monsoon season at the Qomolangma site. The residuum increased correspondingly from morning to afternoon. This enhanced residuum may be explained by an intensification of advection caused by glacial wind, since an intense latent cooling of the surface leads to greater advective flux being directed towards the local land cover. As such advective flux is not caught by the EC system, the residuum increases. Following the suggestions of Foken (2008) and Foken et al. (2010), energy transported by advection over a heterogeneous landscape can also be transferred to the energy within large 

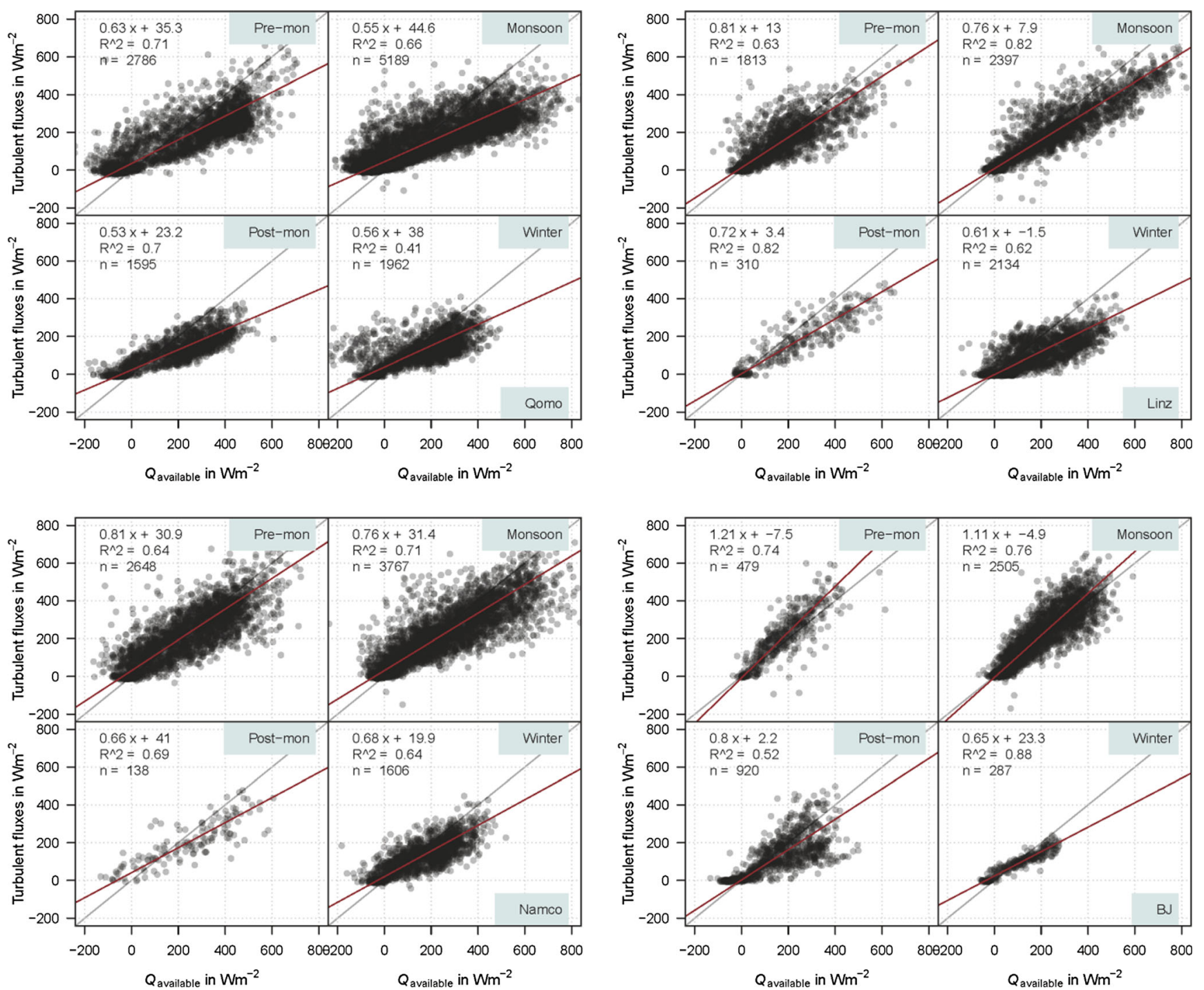

Fig. $5 C_{\mathrm{EB}}$ at the Qomolangma (Qomo), Linzhi (Linz), NamCo (Namc) and Nagqu (BJ) sites

eddies, thus becoming undetectable by the EC system. $Q_{\mathrm{G}}$ values exhibit a downward transfer in the early afternoon at the Qomolangma site; the transfer is upward at the other sites (Fig. 2). This leads to an energy balance over-closure in the evening at Qomolangma. Further, land cover at Qomolangma is

wind direction $[-]$

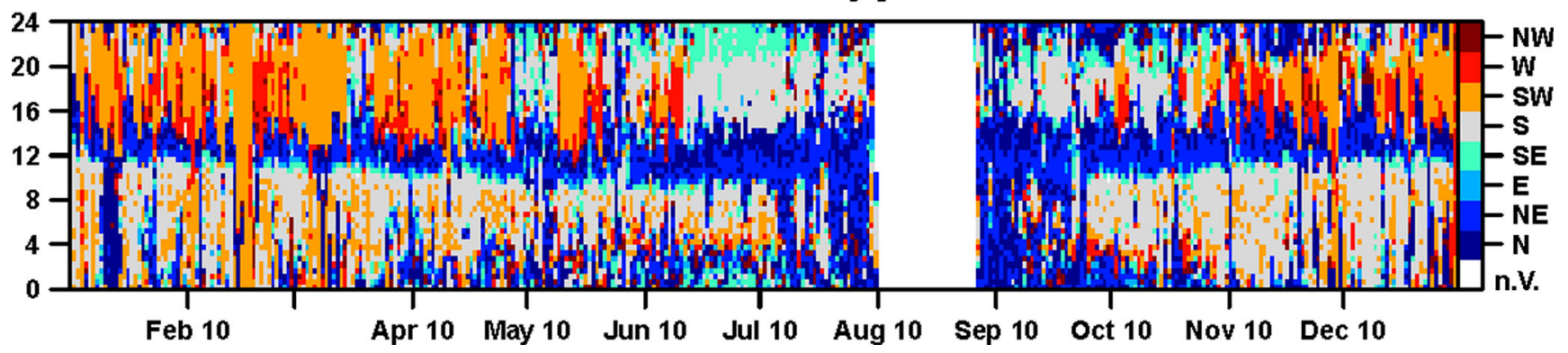

Fig. 6 Diurnal variations in wind direction at the Qomolangma site 
Table $4 C_{\mathrm{EB}}$ and the entropy of the plant functional type $[I(\mathrm{PFT})]$ in a $20 \times 20 \mathrm{~km}^{2}$ region surrounding the flux towers at the four TP sites

\begin{tabular}{lll}
\hline Site & $C_{\mathrm{EB}}$ & $I(\mathrm{PFT})$ \\
\hline Qomo & 0.61 & 1.39 \\
Linz & 0.76 & 1.74 \\
Namc & 0.78 & 1.24 \\
BJ & 1.07 & 0.04 \\
\hline
\end{tabular}

bare soil/gravel, which facilitates sensible heat flux increasing the thermal coupling soil function.

\subsubsection{Landscape heterogeneity and energy balance closure}

We chose the MODIS product with the highest spatial resolution, the MOD13Q1 product $(250 \mathrm{~m})$, for the calculation of the EVI in the $20 \times 20 \mathrm{~km}^{2}$ area surrounding the four flux towers analysed here. The EVI was chosen over the normalised difference vegetation index (NDVI) because of the saturated NDVI-leaf area index (LAI) relation for forest canopies (Huete et al. 2002). The EVI was chosen over the LAI to avoid uncertainties in the MODIS/LAI algorithm. Data selection followed Stoy's method (Stoy et al. 2013).

The MODIS plant functional types (PFT) and EVI values for the $20 \times 20 \mathrm{~km}^{2}$ area surrounding the TP flux towers are shown in Fig. 6. There is a significant negative relation between $C_{\mathrm{EB}}$ and the entropy of the plant functional type $(I)$ in Table 4. The relationship between $C_{\mathrm{EB}}$ and $I(\mathrm{PFT})$ at the Qomolangma site did not follow this rule due to the area's simple land cover. Figure 7 shows that the land cover is most homogeneous at the Nagqu site (Fig. 7d), with low I(PFT) values. The NamCo area has water with negative EVI values (Fig. $7 \mathrm{~g}$ ).

\section{Summary and conclusions}

A 3-year dataset (2008-2010) of EC-measured turbulent fluxes was compiled from four stations on the TP into a standardised workflow: corrections and quality tests were applied using an internationally comparable software package. The typical features of $C_{\mathrm{EB}}$ and the monsoon effect on turbulence fluxes were investigated in this study.

First, the energy flux at the abovementioned four sites is clearly influenced by the monsoon. In the premonsoon period, the sensible heat flux is the major energy source providing heat to the atmosphere, whereas during the monsoon season, the latent heat flux is greater than the sensible heat flux. Other factors
Fig. 7 MODIS MCD12Q1 plant functional types (PFT) for the $20 \times$ $20 \mathrm{~km}^{2}$ area surrounding the Qomolangma (a), Linzhi (b), NamCo (c) and Nagqu-BJ (d) stations on the TP for 2008 and the MODIS MOD13Q1 EVI for the same area, measured on 26 August 2008 at the Qomolangma site (e), 30 July 2008 at Linzhi site (f) and 10 May 2008 at NamCo and Nagqu-BJ sites $(\mathbf{g}, \mathbf{h})$

affecting surface energy flux are topography and location. Third, land cover affects surface energy flux. For example, $Q_{\mathrm{E}}$ is low at the Qomolangma sites even in the monsoon season as its land cover is bare soil/gravel; the heat from radiation heats the surface and increases surface temperatures, which convert to $Q_{\mathrm{H}}$, meaning $Q_{\mathrm{H}}$ remains high, and $>Q_{\mathrm{E}}$, during the monsoon season.

The latent heat flux increases during the monsoon season and exceeds the sensible heat flux, except at the Qomolangma site. The glacial wind effect which occurs in the Qomolangma area influences the nonclosure of the surface energy balance. Enhanced advective flux values caused by the glacial wind effect not captured by the EC measuring system are assumed to be the reason for the higher energy flux residuum during the daytime, especially during the monsoon season.

The energy balance residuum typically indicates overall non-closure in winter (DJF), while a $C_{\mathrm{EB}}$ (or 'turbulent over-closure') occurs at the Nagqu site during the summer. This circumstance seems to depend on ground heat flux, which is higher in the wet season, as related to a higher radiation input on one hand and a thermal decoupling of dry soils on the other. If the latter is typical, then the scale mismatch (turbulence measurements over the dryer upwind region and soil measurements in the wetter regions) is the main reason for the different $C_{\mathrm{EB}}$ values for summer and winter. A turbulent over-closure also exists at Qomolangma in the evenings. This seems to depend on ground heat flux, which exhibits a contrary direction of transference to the other three sites in the early afternoons (Fig. 2) as well as a thermal decoupling of the bare soil surface.

Landscape heterogeneity can also partly explain the cause of energy non-closure, but is not the only reason. In general, the relationship between $C_{\mathrm{EB}}$ and $I(\mathrm{PFT})$ is negative. The $C_{\mathrm{EB}}$ rate increases with the decreasing variance of EVI in the areas around the measuring stations.

Acknowledgments This research was supported by the National Natural Science Foundation of China (Grant No. 91337212), the Chinese National Key Programme for Developing Basic Sciences (Grant No. 2010CB951703), the China Exchange Project (Grant No. 13CDP007), the European Commission (Call FP7-ENV-2007-1, Grant No. 212921) as part of the CEOP-AEGIS project (http://www.ceop-aegis.org/) coordinated by the University of Strasbourg, and the National Natural Science Foundation of China (Grant Nos. 41175008, 40825015 and 40675012). 
a

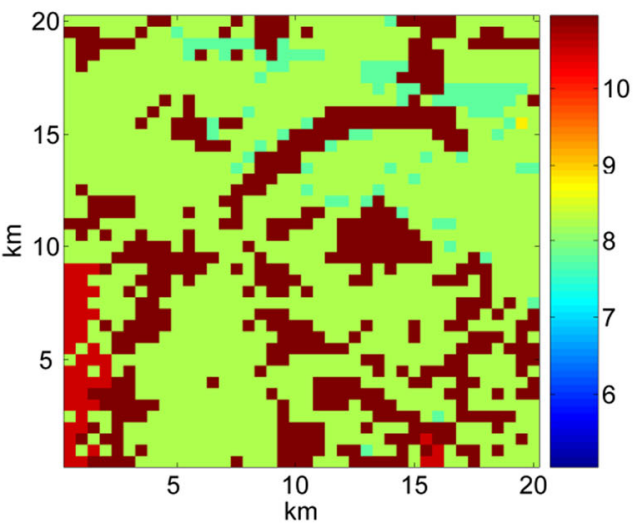

b

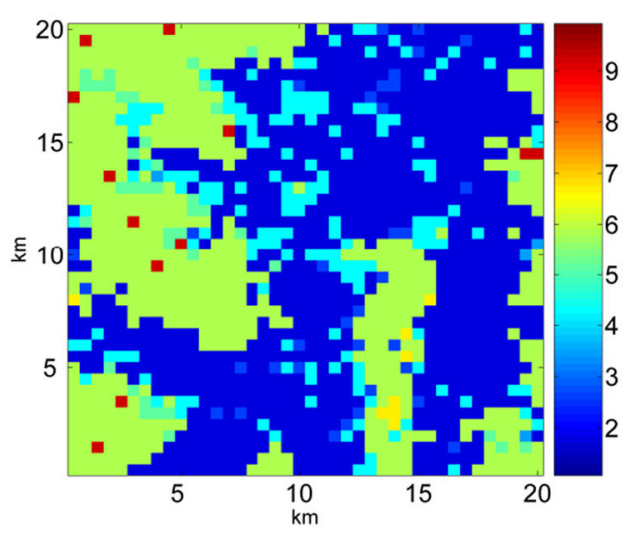

$\mathrm{C}$

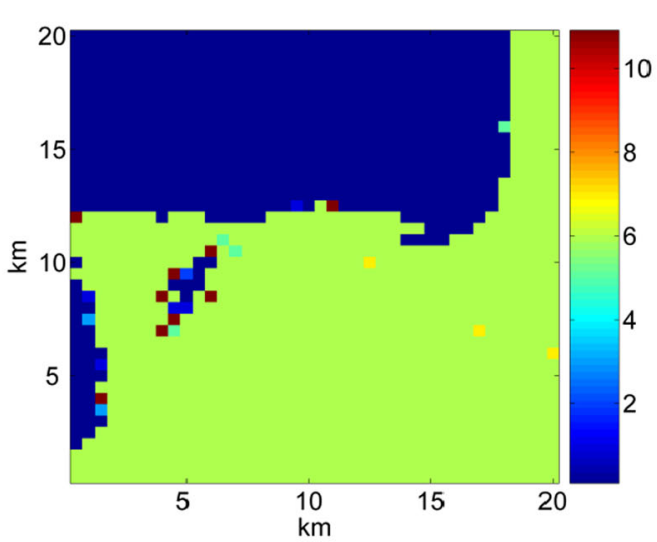

d

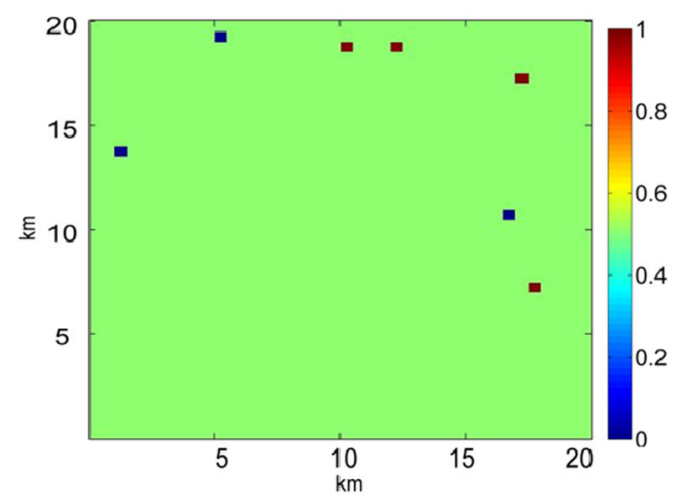

$\mathrm{e}$

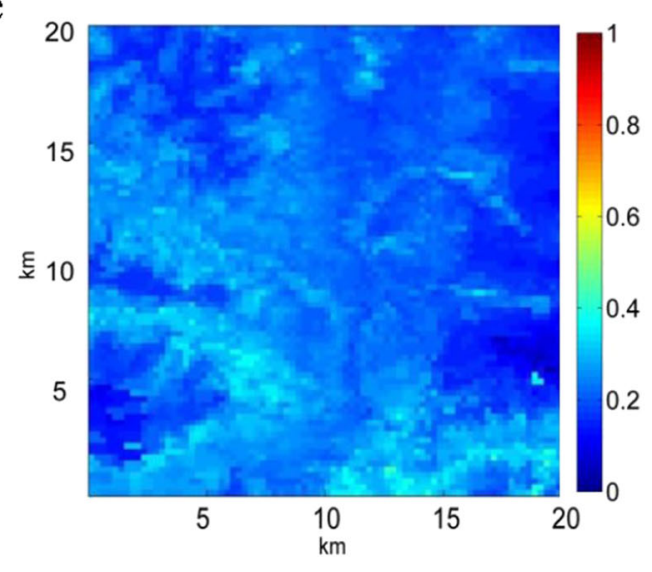

f

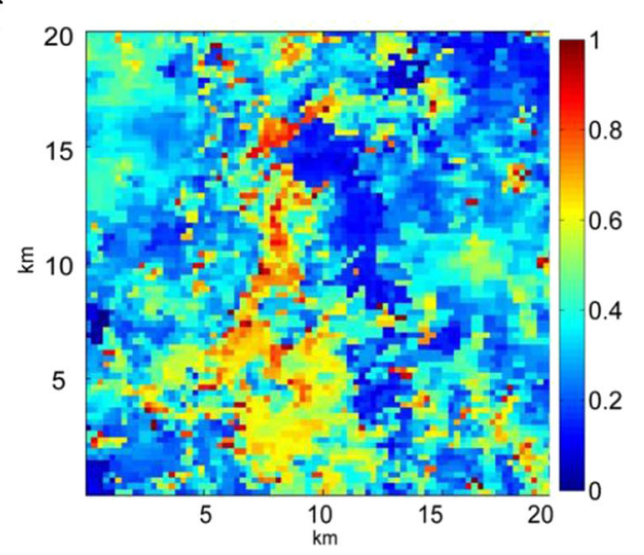

$\mathrm{g}$

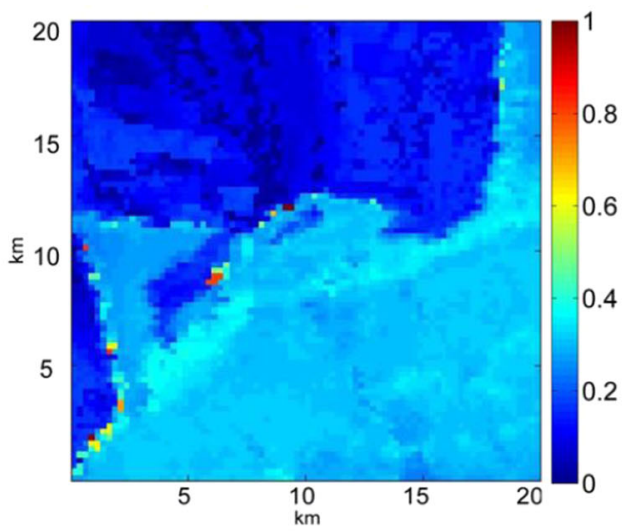

$\mathrm{h}$

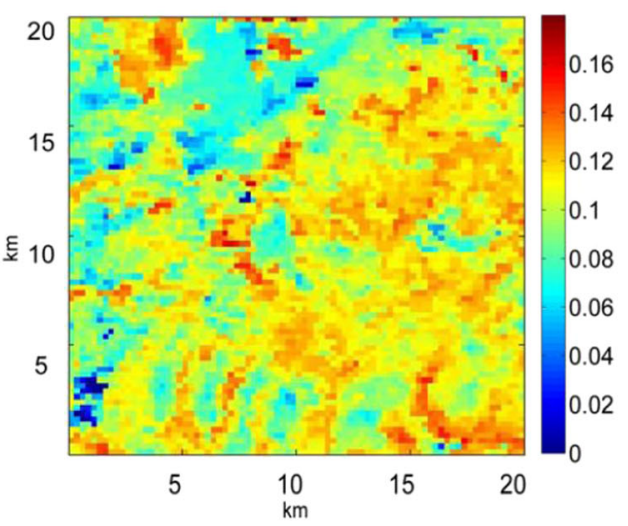


Open Access This article is distributed under the terms of the Creative Commons Attribution License which permits any use, distribution, and reproduction in any medium, provided the original author(s) and the source are credited.

\section{References}

Bian L, Gao Z, Xu Q, Lu L, Cheng Y (2002) Measurements of turbulence transfer in the near-surface layer over the southeastern Tibetan Plateau. Bound Layer Meteor 102:281-300

Bian L, Gao Z, Ma Y, Koike T, Ma Y, Li Y, Sun J, Hu Z, Xu X (2012) Seasonal variation in turbulent fluxes over Tibetan Plateau and its surrounding areas: research note. J Meteorol Soc Jpn 90C:157-171. doi:10.2151/jmsj.2012-C11

Charuchittipan D, Babel W, Mauder M, Leps J.-P, and Foken T (2014) Extension of the averaging time of the eddy-covariance measurement and its effect on the energy balance closure, submitted to Bound.-Lay. Meteorol 1-25

Chen L, Reiter ER, Feng Z (1985) The atmosphere heat source over the Tibetan Plateau: May-August 1979. Mon Weather Rev 113: $1771-1790$

Flohn H (1957) Large-scale aspects of the "summer monsoon" in the South and East Asia. J. Meteor. Soc. Japan, 75th Ann. 180-186

Foken T (2008) The energy balance closure problem: an overview. Ecol Appl 18:1351-1367

Foken T, Wichura B (1996) Tools for quality assessment of surface-based flux measurements [J]. Agric For Meteorol 78:83-105

Foken T, Göckede M, Mauder M, Mahrt L, Amiro BD, Munger JW (2004) Post-field data quality control. In: Lee X, Massman W, Law B (eds) Handbook of micrometeorology: a guide for surface flux measurement and analysis. Kluwer, Dordrecht, pp 181-208

Foken T, Aubinet M, Finnigan JJ, Leclerc MY, Mauder M, Paw KTU (2011) Results of a panel discussion about the energy balance closure correction for trace gases. Bull Amer Meteor Soc 92: ES13-ES18. doi:10.1175/2011BAMS3130.1

Foken $\mathrm{T}$ et al (2010) Energy balance closure for the LITFASS-2003 experiment. Theor Appl Climat 101:149-160

Fuehrer PL, Friehe CA (2002) Flux corrections revisited [J]. BoundLayer Meteorol 102:415-457

Gu S, Tang YH, Cui XY, Kato T, Du MY, Li YN, Zhao XQ (2005) Energy exchange between the atmosphere and a meadow ecosystem on the Qinghai-Tibetan Plateau. Agr Forest Meteorol 129:175-185. doi:10.1016/j.agrformet.2004.12.002

Heusinkveld BG, Jacobs AFG, Holtslag AAM, Berkowicz SM (2004) Surface energy balance closure in an arid region: role of soil heat flux. Agric For Meteor 122:21-37

Huete A, Didan K, Miura T, Rodriguez EP, Gao X, Ferreira LG (2002) Overview of the radiometric and biophysical performance of the MODIS vegetation indices. Remote Sens Environ 83(1-2):195-213

Ji G, Yao LC, Yuan FM, Yang HY (1986) Characteristics of surface and atmosphere heating field over the Tibetan Plateau in winter in 1982. Sci China (B) 31(8):876-888, in Chinese

Kim J, and co-authors (2001) On measuring and modeling surface energy partitioning in a Tibetan prairie during GAMB.10P 1998. Proceedings of the Fifth International Study Conference on GEWEX in Asia and GAM E, World Climate Research Programme (WCRP), Nagoya University, Nagoya, Japan, 18-25

Koike T, Yasunari T, Wang J and Yao T (1999) GAME-Tibet IOP Summary Report, paper presented at the 1st International Workshop on GAME-Tibet, Xi'an, China, 11-13 January

Li C, Yanai M (1996) The onset and interannual variability of the Asian summer monsoon in relation to land-sea thermal contrast. J Clim 9: 358-375
Li C, Duan T, Haginoya S, Chen L (2001) Estimates of the bulk transfer coefficients and surface fluxes over the Tibetan Plateau using AWS data. J Meteor Soc Japan 79(2):625-635

Li M, Ma Y, Zhong L (2012) The turbulence characteristics of atmospheric surface layer on the north slope of Mt. Everest region in the spring of 2005. J Meteorol Soc Jpn 90C:185-193. doi:10.2151/jmsj. 2012-C13

Liebethal C, Foken T (2003) On the significance of the Webb correction to fluxes [J]. Bound-Layer Meteorol 109:99-106

Liebethal C, Foken T (2004) On the significance of the Webb correction to fluxes [J]. Corrigendum Boundary-Layer Meteorol 113:301

Liu HP, Peters G, Foken T (2001) New equations for sonic temperature variance and buoyancy heat flux with an omnidirectional sonic anemometer [J]. Bound-Layer Meteorol 100: 459-468

Liu S, Li S-G, Yu G-R, Sun X-M, Zhang L-M, Hu Z-M, Li Y-N, Zhang $X-Z$ (2009) Surface energy exchanges above two grassland ecosystems on the Qinghai-Tibetan Plateau. Biogeosci Discuss 6:91619192. doi:10.5194/bgd-6-9161-2009

Ma Y, Su Z, Koike T, Yao T, Ishikawa H, Ueno K, Menenti M (2003) On measuring and remote sensing surface energy partitioning over the Tibetan Plateau - from GAME/Tibet to CAMP/Tibet. Phys Chem Earth 28:63-74. doi:10.1016/s1474-7065(03)00008-1

Ma YM, Fan SH, Ishikawa H, Tsukamoto O, Yao T, Koike T, Zuo H, Hu $\mathrm{Z}, \mathrm{Su} Z$ (2005) Diurnal and inter-monthly variation of land surface heat fluxes over the central Tibetan Plateau area. Theor Appl Climatol 80:259-27

Ma Y, Zhong L, Su Z et al (2006) Determination of regional distributions and seasonal variations of land surface heat fluxes from Landsat-7 ETM data over the central Tibetan Plateau area. J Geophys Res 111: D10305. doi:10.1029/2005JD006742

Mauder M and Foken T (2011) Documentation and instruction manual of the eddy covariance software package TK3, Work Report University of Bayreuth, Dept. of Micrometeorology, ISSN: 1614-8916, pp. 46, 58

Mauder M, Liebethal C, Göckede M, Leps JP, Beyrich F, Foken T (2006) Processing and quality control of flux data during LITFASS-2003. Boundary-Layer Meteoro 121:67-88

Mauder M, Jegede OO, Okogbue EC, Wimmer F, Foken T (2007) Surface energy balance measurements at a tropical site in West Africa during the transition from dry to wet season. Theor Appl Climatol 89:171-183

Moore CJ (1986) Frequency response corrections for eddy correlation systems [J]. Bound-Layer Meteorol 37:17-35

Qian ZA and Jiao YJ (1997) Advances and problems on Qinghai-Xizang Plateau meteorology research. Advances in Earth Sciences, 12 (31, 207-216; in Chinese)

Rebmann C, Göckede M, Foken T, Aubinet M, Aurela M, Berbigier P, Bernhofer C, Buchmann N, Carrara A, Cescatti A, Ceulemans R, Clement R, Elbers JA, Granier A, Gr"unwald T, Guyon D, Havrankova K, Heinesch B, Knohl A, Laurila T, Longdoz B, Marcolla B, Markkanen T, Miglietta F, Moncrieff J, Montagnani L, Moors E, Nardino M, Ourcival JM, Rambal S, Rannik U, Rotenberg E, Sedlak P, Unterhuber G, Vesala T, Yakir D (2005) Quality analysis applied on eddy covariance measurements at complex forest sites using footprint modelling. Theor Appl Climatol 80: 121-141

Schotanus P, Nieuwstadt FTM, DeBruin H (1983) Temperature measurement with a sonic anemometer and its application to heat and moisture fluxes [J]. Bound-Layer Meteorol 26:81-93

Shi Q, Liang S (2014) Surface-sensible and latent heat fluxes over the Tibetan Plateau from ground measurements, reanalysis, and satellite data. Atmos Chem Phys 14:5659-5677. doi:10.5194/acp-14-5659-2014

Stoy PC, Mauder M, Foken T, et al (2013) A data-driven analysis of energy balance closure across FLUXNET research sites: the role of landscape scale heterogeneity, Agricultural and Forest Meteorology, Volumes 171-172, 15, Pages 137-152 
Sun F, Ma Y, Li M, Ma W, Tian H, Metzger S (2007) Boundary layer effects above a Himalayan valley near Mount Everest. Geophys Res Lett 34, L08808. doi:10.1029/2007GL029484

Tanaka K, Tamagawa I, Ishikawa H, Ma Y, Hu Z (2003) Surface energy budget and closure of the eastern Tibetan Plateau during the GAMETibet IOP 1998. J Hydrol 283:169-183. doi:10.1016/s00221694(03)00243-9

Twine TE, Kustas WP, Norman JM, Cook DR, Houser PR, Meyers TP, Prueger JH, Starks PJ, Wesley ML (2000) Correcting eddycovariance flux underestimates over a grassland. Agr Forest Meteorol 103:279-300. doi:10.1016/S0168-1923(00)00123-4

Van der Velde R, Su Z, van Oevelen P, Wen J, Ma Y, Salama MS (2012) Soil moisture mapping over the central part of the Tibetan Plateau using a series of ASAR WS images. Remote Sens Environ 120(2012):175-187

Vickers D, Mahrt L (1997) Quality control and flux sampling problems for tower and aircraft data $[\mathrm{J}]$. J Atmos Ocean Technol 14:512-526

Wang J, Kim J and Liou Y, et al. (1999) Energy balance analysis and onedimensional simulation of land surface process in a short-grass site of Central Tibetan Plateau. Proceedings of the 1st International Workshop on GAME-Tibet, 73-76

Webb EK, Pearman GI, Leuning R (1980) Correction of flux measurements for density effects due to heat and water-vapor transfer [J]. Q J R Meteorol Soc 106:85-100

Wilczak JM, Oncley SP, Stage SA (2001) Sonic anemometer tilt correction algorithms [J]. Bound-Layer Meteorol 99:127-150
Xu S, Gao Y (1962) The monsoon phenomenon of Tibetan Plateau. Acta Geographic Sinica 28(2):111-123 (in Chinese)

$\mathrm{Xu}$ X, Chen L and Zhou M (2002) The Second Tibetan Plateau Experiment of Atmospheric Sciences: TIPEX-GAME/TIBET. China Meteorological Press, $236 \mathrm{pp}$

Yang K, Wang JM (2008) A temperature prediction-correction method for estimating surface soil heat flux from soil temperature and moisture data. Sci China Ser D Earth Sci 51(5):721-729

Yang K, Koike T, Ishikawa H, Ma Y (2004) Analysis of the surface energy budget at a site of GAME/Tibet using a single-source model. J Meteorol Soc Jpn 82(1):131-153

Yao J, Zhao L, Gu L, Qiao Y, Jiao K (2011) The surface energy budget in the permafrost region of the Tibetan Plateau. Atmos Res 102:394 407. doi:10.1016/j.atmosres.2011.09.001

Yeh DZ, Gao YX (1979) The meteorology of the Qinghai-Xizang (Tibet) Plateau. Science, Beijing, p 278 (in Chinese)

Yeh TC, Dao S and Li M (1957) The abrupt change of circulation over the North Hemisphere during June and October, The Atmosphere and the Sea in Motion, Rossy Memorial Volume, The Rockefeller Institute Press, 249-267

Zhang JJ, Zhu BZ, Zhu PK, Weng DM, Sun GW, Lu JN, Peng YQ and Wang YZ (1988) Advances in the Qinghai-Xizang Plateau Meteorology. Sciences Press, Beijing, pp.268 (in Chinese)

Zhang G, Kang S, Fujita K, Huintjes E, Xu J, Yamazaki T, Haginoya S, Wei Y, Scherer D, Schneider C, Yao T (2013) Energy and mass balance of Zhadang glacier surface, central Tibetan Plateau. J Glaciol 59:137-148. doi:10.3189/2013JoG12J152 